\title{
Uma revisão do conceito de texto e suas implicações para os estudos filológicos
}

\section{A review of the concept of text and its implications for philological studies}

\author{
Luiz Eleildo Pereira Alves* \\ Universidade Estadual do Ceará, Fortaleza, Ceará, Brasil \\ Expedito Eloísio Ximenes ${ }^{* *}$ \\ Universidade Estadual do Ceará, Fortaleza, Ceará, Brasil
}

\begin{abstract}
Resumo: As transformações conceituais da Linguística, nos últimos anos, têm proposto uma revisão de conceitos caros aos estudos da linguagem; dentre eles, o conceito de texto. Ultimamente, defende-se, sobretudo na Linguística Textual, que esse objeto deve ser contemplado para além de seus componentes materiais. Tendo em vista a relevância dessa discussão, julgamos ser conveniente apresentar neste artigo como as metamorfoses conceituais pelas quais a Filologia passou têm, ao nosso ver, uma intrínseca relação com o status que o texto veio incorporando, sobretudo, dentro dos estudos da Linguística Textual. Dessa forma, neste trabalho, aprofundamos a discussão que já sinalizamos em Alves (2016), onde discutimos o conceito de Filologia Textual, já apresentado em trabalhos como os de Santos e Souza (2012), Gama e Telles (2006) e Teixeira (2008). Argumentamos no sentido de mostrar como perspectivas teóricas da Linguística de Texto tendem a contribuir com o desenvolvimento das pesquisas no campo da Filologia, estabelecendo uma interface entre essas duas áreas do estudo da linguagem.
\end{abstract}

Palavras-chave: Filologia. Texto. Linguística textual.

\begin{abstract}
The conceptual transformations within Linguistics in recent years have proposed a revision of concepts that are dear to language studies, among which is the concept of text. Ultimately, it is argued, especially within Text Linguistics, that this object must be contemplated beyond its material components. In view of the relevance of this discussion, we think it is convenient to present in this article how the conceptual metamorphoses which Philology has faced, in our view, have an intrinsic relation with the status that the text has incorporated, above all, within the studies of Textual Linguistics. Thus, in this work, we deepen the discussion that we have already pointed out in Alves (2016), where we discuss the concept of Textual Philology, already presented in works such as Santos e Souza (2012), Gama e Telles (2006) and Teixeira (2008). We show how theoretical perspectives of Text Linguistics tend to contribute to the development of research in the field of Philology, establishing an interface between these two areas of language study.
\end{abstract}

Keywords: Philology. Text. Text Linguistics.

\footnotetext{
* Professor substituto do Curso de Letras e doutorando em Linguística Aplicada pelo Programa de Pósgraduação em Linguística Aplicada da Universidade Estadual do Ceará, Fortaleza, CE, Brasil; eleildoa@gmail.com

** Professor doutor e pesquisador no Programa de Pós-graduação em Linguística Aplicada e no Mestrado interdisciplinar em História e Letras da Universidade Estadual do Ceará, Fortaleza, CE, Brasil; eloisio22@hotmail.com
} 


\section{INTRODUÇÃo}

A atual concepção de língua(gem) adotada no campo dos estudos linguísticos - sobretudo no campo da Linguística Textual - reclama, para as demais ciências que trabalham com o texto, a abordagem desse objeto enquanto um construto para além da materialidade. Entender os conceitos de língua(gem) e texto sob essa nova perspectiva implica uma compreensão de sujeito enquanto ator social co-participante do ato enunciativo.

Tendo em vista a relevância dessa discussão, que desenvolvemos em nossa dissertação de mestrado (Alves, 2016), apresentamos neste artigo um recorte desse trabalho anterior por julgarmos ser conveniente apresentar como as metamorfoses conceituais pelas quais a Filologia passou têm uma intrínseca relação com o status que o texto veio incorporando, sobretudo, dentro dos estudos da Linguística Textual.

Dessa forma, discutimos, inicialmente, o que se pensa(va) a respeito do conceito de Filologia, fazendo um breve apanhado desde o trabalho desenvolvido pelos povos helenísticos, passando por um período de ostracismo, até o seu ressurgimento ao lado das 'ciências modernas', a partir dos anos finais do século XX, chegando aos dias de hoje. Depois, buscamos mostrar como os conceitos adotados pelos pesquisadores da Linguística de Texto tendem a contribuir com o desenvolvimento das pesquisas no campo da Filologia, realizando uma interface entre essas duas áreas do estudo da linguagem. Recordamos as palavras de Queiroz (2015, p. 10), que considera que "sendo o texto um construto multidisciplinar, não há como fugir à interface da Linguística de Texto com as diversas ciências que dão conta do estudo da linguagem".

É essa interface teórica entre as ciências citadas acima, que têm como objeto de estudo os processos de construção, divulgação e interpretação dos textos, que buscamos discutir na próxima seção, começando pela própria revisão do conceito de Filologia até chegarmos às contribuições da Linguística Textual.

\section{PERCURSO E DEFINIÇÃo dOS ESTUdOS FILOLÓGICOS}

A história de um povo, sua cultura, suas transformações e crenças, dentre outras questões, são informações importantíssimas para sabermos de onde viemos, onde estamos e imaginarmos para onde vamos. Ao longo do tempo, os povos de todo o mundo buscaram transmitir informações através de registros de diversos tipos que foram sendo sistematizados até chegarmos à condição de evidenciar tais informações por meio da escrita.

De acordo com Coulmas (2014, p. 11) “os sistemas de escrita e a língua escrita são objetos surpreendentes, de grande complexidade, testemunhos do engenho humano e da nossa determinação em criar nosso próprio universo". Ora, com o intuito de investigar esse universo humano manifestado em formas escritas, os filólogos, através de um minucioso trabalho de leitura e edição desses registros, contribuem para o desenvolvimento das pesquisas linguísticas e de outras ciências humanas através do caráter interdisciplinar que é inerente à Filologia.

Antes de avançarmos pelo caminho que, para o Mundo Ocidental, tem início entre os povos alexandrinos, faz-se necessário conceituarmos o que se pensa sobre 
Filologia. De antemão, é válido ressaltarmos que não existe um consenso entre os estudiosos da área a respeito do que seria, precisamente, esta ciência. A seguir, elencamos algumas definições.

O Dicionário de Linguística (Dubois et al., 2011, p. 258) elucida o caráter histórico do labor filológico ao definir Filologia como sendo

uma ciência histórica que tem por objeto o conhecimento das civilizações passadas através dos documentos escritos que elas nos deixaram; estes nos permitem compreender e explicar as sociedades antigas.

Gaetano Righi (1967), adotando uma visão mais clássica e, a nosso ver, mais material do trabalho filológico, afirma que

\begin{abstract}
a filologia é esse interesse por conservar os textos, esse afã por fixar com exatidão os documentos, por estabelecê-los e documentá-los para poder descrevê-los fidedignamente e reproduzi-los de um modo sensível como depósitos de sabedoria certa do passado. (Righi, 1967, p. 13, tradução nossa $)^{1}$.
\end{abstract}

Já para Ximenes (2013, p. 178), o papel da Filologia é resgatar a produção textual de uma época, possibilitando, assim, conhecermos a história da língua e suas mudanças sociais, compreendendo "todas as manifestações vividas por uma comunidade, expressas nas entrelinhas dos textos". Este autor afirma que uma função básica da Filologia é a recuperação de textos escritos em tempos pretéritos. Para ele, é essa característica primeira que nos ocorre quando pensamos no termo.

Santiago-Almeida (2011, p. 2), por sua vez, compreende a Filologia a partir de dois sentidos: no sentido amplo e no sentido estrito. Para ele:

\begin{abstract}
No sentido mais amplo (lato sensu), a filologia dedica-se ao estudo da língua em sua amplitude - linguístico, literário, crítico-textual, sócio-histórico etc. - no tempo e no espaço, tendo como objeto de estudo o texto escrito, literário e não-literário. [...]

No sentido mais estreito (stricto sensu), a filologia se concentra no texto escrito, primordialmente literário, para estabelecê-lo, fixá-lo, restituindolhe à sua genuinidade, e prepará-lo para publicação.
\end{abstract}

A definição de Santiago-Almeida, como podemos perceber, abrange tanto o viés linguístico decorrente do trabalho filológico, quanto o viés literário. Dessa definição, depreendemos que, stricto sensu, a Filologia pode ser tida como sinônimo de Crítica Textual. Autores como Castro (1992) também apresentam essa característica dos estudos filológicos. Para ele, a Filologia é a:

Ciência que estuda a gênese e a escrita dos textos, a sua difusão e a transformação dos textos no decurso da sua transmissão, as características materiais e o modo de conservação dos suportes textuais, o modo de editar os textos com respeito máximo pela intenção manifesta do autor (Castro, 1992, p. 124, apud Megale e Cambraia, 1999, p. 1).

\footnotetext{
${ }^{1}$ No original: “[...] filología es ese interés por conservar los textos, ese afán por fijar con exactitud los documentos, por estabelecerlos y documentarlos para poderlos describir fidedignamente y reproducirlos de un modo sensible como depósitos de la sabiduría cierta del passado".
} 
Como pudemos perceber, não há, precisamente, uma definição consensual quanto ao termo Filologia. No entanto, é inegável que os estudos filológicos ocidentais têm seu berço entre os povos helenizados, na região de Alexandria, por volta do século IV a.C., no período helenístico.

De acordo com Spina (1977), a fase helenística (também conhecida como alexandrina), que se estende aproximadamente de 322 a 116 a.C., foi o período em que a Grécia não só se voltou para repensar seu passado ${ }^{2}$, mas também exportou formas de criação para diversos outros lugares do mundo. Nesse momento, "eruditos de toda procedência se sucederam como bibliotecários da famosa biblioteca de Alexandria, que [...] se tornou o maior centro de cultura helênica da Antiguidade" (Spina, 1977, p. 60). $\mathrm{O}$ acervo encontrado na biblioteca de Alexandria era bastante numeroso ${ }^{3}$ e, como aponta Spina (1977), por consequência da ordenação e catalogação desse acervo, começaram a surgir problemas pertinentes à autenticidade das obras, à vida dos autores e, posteriormente, à preparação de textos para o público e para as escolas.

Spina (1977) afirma que o trabalho desenvolvido por sábios bibliotecários que se sucederam em Alexandria, como Zenódoto de Éfeso (autor da primeira edição crítica dos poemas de Homero), Eratóstenes (o primeiro a se chamar 'filólogo'), Aristófanes de Bizâncio (autor de uma edição exemplar dos poemas de Homero e de edições críticas de Alceu, Anacreonte, Píndaro etc.) e Aristarco (que fez duas edições de Homero com Aristófanes de Bizâncio, constituindo a culminação da investigação filológica em Alexandria) foi fundamental no serviço de restauração de textos literários antigos, "tornando-os inteligíveis às gerações da época, sobretudo os poemas épicos de Homero". (Spina, 1977, p. 61).

Câmara Jr. (1975) ressalta que essa atividade de edição dos textos dos antigos poetas da Grécia, principalmente de Homero, se fazia muito necessária, pois a literatura grega usava dialetos locais. Assim, a atividade dos filólogos era, também, a de estudar as fases da língua grega, comparar esses dialetos e produzir um manuscrito mais ou menos consensual através de um grande processo de Crítica Textual e de estudos de caráter comparativo.

Dessa forma, se dissemos, anteriormente, que não há um consenso entre os estudiosos da área acerca do que seria precisamente Filologia, o mesmo não acontece quando falamos das origens dessa ciência, pois todos concordam que a Biblioteca de Alexandria foi o grande centro ocidental das pesquisas filológicas. Santos e Souza (2012), por exemplo, afirmam que Alexandria, dentre as tradições culturais que desenvolveram "práticas filológicas", foi a que mais se destacou, chegando a se tornar parâmetro para os intelectuais do Humanismo Renascentista, por volta do século XVI, na Europa. Segundo Bassetto (2001, p. 28), nessa época, "surgem renomados humanistas e a filologia é retomada com a pesquisa 'real' dos antigos, buscando uma

\footnotetext{
2 Segundo Spina (1977), nesse período a Grécia retomava seu apogeu criador revisitando a obra de inúmeros autores antigos. Na filosofia, Platão, Sócrates e Aristóteles; no teatro, Sófocles, Eurípides e Aristófanes; na historiografia com Heródoto, Tucídides e Xenofonte; e na eloquência, Isócrates e Demóstenes.

${ }^{3}$ Spina (1977, p. 60) afirma que o acervo da biblioteca de Alexandria era composto por "490 mil volumes e outros 43 mil colocados, por falta de espaço, no museu Serapeum, contíguo à Biblioteca”.
} 
explicação compreensiva dos textos". Bassetto (2001) elenca alguns dos principais trabalhos desenvolvidos nessa época:

[...] é preciso citar especialmente a trilogia formada por José Justo Escalígero (1540-1653), Cláudio de Saumaise (1588-1653) e Isaac Casaubon (1559-1614). Ligado a esses três e, de certa forma, seu guia, Júlio César Escalígero (1484-1558), exerceu grande influência tanto pela disputa mantida com Erasmo de Roterdam (1467-1536) como por suas edições das obras de Teofrasto e de Aristóteles, a publicação dos seus Poetices Libri VII (1561), de teoria literária, e o De Causis Linguae Latinae, considerada a primeira proposta de uma gramática latina específica. Como humanista, médico e poeta, Júlio César Escalígero é o modelo do "sábio" ou "filósofo" na acepção grega e latina. O termo "filólogo" volta a qualificar os expoentes intelectuais, e a filologia ressurge com vigor, como se vê na obra de Guillaume Budé ou Guliermus Budaeus (1467-1540), dito o Erasmo da França, De Philologia Libri II (1532), tendo sido um dos primeiros a escrever também em francês, além de obras redigidas em grego e latim (Bassetto, 2001, 28).

De acordo com Auerbach (1972, p. 12),

os esforços dos humanistas se orientavam no sentido de estudar e imitar os autores da antiguidade grega e latina, e a escrever num estilo semelhante ao deles, quer em latim, que ainda era a língua dos eruditos, quer em sua língua materna.

A tarefa dos humanistas era, então, "encontrar os manuscritos que ainda existissem, compará-los em seguida e tentar extrair o texto original, aquele redigido pelo autor".

Tal trabalho se fazia pertinente porque, na atividade de copiar à mão inúmeros textos, os erros de cópia eram muito comuns, muitas vezes por uma atitude involuntária do copista, que ao tirar os olhos da folha acabava perdendo uma palavra (o salto-bordão), ou mesmo por uma atitude maliciosa do copista que queria realmente alterar o manuscrito. Assim, a tendência dos estudos filológicos, ainda no século XVI, era muito parecida com aquela atividade exercida pelos helenísticos em Alexandria. Essa forma de pensar a atividade filológica perdurou até o século XIX, passando pelo surgimento do método de edição crítica de Karl Lachmann ${ }^{4}$, durante as décadas finais do século XVIII, até as críticas feitas por Bédier ${ }^{5}$. Esses estudiosos ainda tinham uma

\footnotetext{
${ }^{4}$ De acordo com Cambraia (2005), Karl Lachmann (1793-1851) foi o primeiro a constituir um método mais rigoroso para a fixação dos textos. Esse método ficou conhecido como método lachmanniano, que, sinteticamente, dividia-se em duas partes: a recensão e a emenda. Para Timpanaro (2002 apud Cambraia, 2005, p. 52), de todos os critérios estabelecidos por Lachmann, a sua contribuição mais pessoal diz respeito à "formulação de critérios para determinar mecanicamente, sem se recorrer ao juízo (lat. indicium) do editor, qual, dentre várias lições, remonta ao arquétipo", ou seja, ao modelo ou exemplar mais próximo do original.

${ }^{5}$ O modelo de Crítica Textual de Lachmann foi especialmente criticado por Joseph Bédier (1864-1938), que embora tenha usado o método em um primeiro momento de seus trabalhos de edição, rejeitouo, posteriormente, "convencido de que o método anteriormente seguido conduzia, quase sempre, à distribuição do conjunto de manuscritos a uma tradição de ramos bífidos, o que praticamente inviabilizava a escolha mecânica de variantes" (Cambraia, 2005, p. 52). Com base nisso, "defendeu o método de editar textos com base em um 'bom manuscrito', publicado quase sempre sem retoques e acompanhado de notas que marcam, como nos diz o próprio Bédier (1928, p. 177), um retorno na direção da técnica dos antigos humanistas" (Cambraia, 2005, p. 52).
} 
latente preocupação com a preservação do 'sentido' do texto ideal. Aquele que não estaria corrompido. "Portanto, caberia ao filólogo resgatar esse sentido verdadeiro" (Santos; Souza, 2012, p. 16).

No século XIX, surge outra corrente dos estudos filológicos fortemente marcada pelo comparativismo das línguas com base em suas gramáticas, na tentativa de estabelecer relações entre essas línguas e classificá-las em famílias. De acordo com Gabas Jr. (2012, p. 86), nesse período William Jones, juiz inglês que estava na Índia, propôs que o latim, o grego e o sânscrito eram línguas aparentadas. Jones

\begin{abstract}
não apenas demonstrou, com os métodos de correspondência de som, que tal afirmação era possível de ser comprovada, como também hipotetizou que as três línguas eram derivadas de uma outra língua, possivelmente já extinta (hoje sabemos que é o protoindo-europeu) (Gabas Jr., 2012, p. 86).
\end{abstract}

Essas descobertas proporcionaram, segundo Gabas Jr. (2012), o começo da Linguística Histórica, que se concentrou nas línguas indo-europeias por conta da sua numerosa quantidade de registros históricos.

Diante desse contexto de descobertas, diversos pesquisadores começaram a estudar tais fenômenos em línguas ainda não exploradas. Bassetto (2001) considera que o método histórico-comparatista deixou muitas lacunas em suas análises; no entanto, pondera o autor que são inegáveis as influências desse método nos estudos das línguas como o latim e o grego antigo, a partir dos quais podemos descobrir inúmeras interseções entre essas e as línguas modernas.

Ximenes (2013) afirma que a concepção de Filologia vigente até o final do século XIX era de caráter globalizante, por envolver aspectos sócio-históricos e fazer interface com áreas como a Paleografia, a Diplomática e a Codicologia ${ }^{6}$, com vistas à compreensão dos textos. No início do século XX, no entanto, tais estudos foram postos em segundo plano diante do afã causado pela emergência da Linguística enquanto ciência do século.

Neste ponto, parece-nos coerente abordarmos a querela entre Filologia e Linguística, criada a partir do surgimento desta última ciência. Para Ximenes (2013), daí surge a "crise de identidade" da Filologia. Tal ocorrência, na visão desse autor, é consequente da tendência natural do ser humano de compartimentalizar as coisas, embora isso nunca seja feito de modo claro.

De acordo com Marquillhas (2008), o marco da segmentação entre Linguística e Filologia foi a importante afirmação dos neogramáticos em seu manifesto, no qual declararam que "as gramáticas das línguas de todas as épocas e de todos os lugares têm natureza semelhante e não se degradam com o tempo. São qualitativamente iguais em todos os contextos espaciais e temporais" (Marquilhas, 2008, p. 19). Dessa forma, seria desnecessário o exercício de investigar e comparar línguas a fim de se chegar à origem

\footnotetext{
${ }^{6}$ Cambraia (2005), tomando Filologia como sinônimo de Crítica Textual, considera que essas áreas do conhecimento têm um forte impacto no trabalho de edição de textos. Baseando-se na definição do próprio autor, podemos considerar Paleografia como um estudo das escritas antigas, como se constituíram sócio-historicamente os sistemas de escrita, relacionando determinada forma de escrita a um período específico; a Diplomática consiste no estudo dos documentos, em especial os jurídicos, entendendo-se documentos como qualquer informação escrita de algum conhecimento; a Codicologia trata do códice, ou seja, o livro manuscrito, e compreende os diversos aspectos de confecção do material escrito, ou seja, a confecção do livro, sua ilustração etc.
} 
de todas elas. Tal afirmação teve como consequência o desânimo pelos estudos comparativistas. A partir de então, conforme entendem vários autores da área, a Filologia passou a ser concebida puramente como uma atividade de Crítica Textual, separando-se dos estudos linguísticos e literários.

Outra questão a respeito da qual não há consenso entre os pesquisadores da Filologia diz respeito ao lugar desta dentro das ciências da linguagem. Alguns autores consideram Linguística e Filologia como ciências paralelas, mas outros veem a Filologia como uma área de pesquisa dentro dos estudos linguísticos; alguns, ainda, afirmam que a Filologia é uma ciência macro, e seria a Linguística um desdobramento desta. A nosso ver, Filologia e Linguística são ciências que, apesar de possuírem pontos de interseção, distinguem-se, uma vez que nem todas as investigações do campo linguístico podem ser abarcadas dentro dos estudos filológicos e vice-versa. No entanto, não podemos deixar de considerar que a Filologia, como todas as ciências modernas, possui um caráter interdisciplinar, o que permite diálogos dessa não só com a Linguística, mas também com a História, a Sociologia, a Antropologia etc.

É por conta da dimensão interdisciplinar que a Filologia possui que Spina (1977 p. 75-77) classifica em três funções básicas a atividade filológica:

$\left.1^{a}\right)$ Função substantiva, em que ela se concentra no texto para explicá-lo, restituí-lo à sua forma genuína e prepará-lo tecnicamente para publicação;

$\left.2^{a}\right)$ Função adjetiva, em que ela deduz, do texto, aquilo que não está nele: a determinação de autoria, a biografia do autor, a datação do texto, a sua posição na produção literária do autor e da época, bem como a sua avaliação estética (valorização);

$\left.3^{a}\right)$ Função transcendente, em que o texto deixa de ser um fim em si mesmo da tarefa filológica, para se transformar num instrumento que permite ao filólogo reconstituir a vida espiritual de um povo ou de uma comunidade em determinada época. A individualidade ou a presença do texto praticamente desaparece, pois o leitor, abstraído do texto, apenas se compraz no estudo que dele resultou.

Além dessas definições, Spina (1977) afirma que a Filologia se concentra no texto escrito para explicá-lo e prepará-lo para ser publicado. Assim, seria papel do filólogo tornar essa materialidade textual inteligível e evidente, mesmo que, para isso, seja necessário recorrer a outras áreas como a Literatura, a Métrica etc. Acreditamos que a classificação feita por Spina é bastante abrangente e permite-nos compreender os diversos exercícios que tocam à atividade do filólogo, a respeito do que argumentamos a seguir:

- A função substantiva liga-se ao papel mais material do labor de edição de textos, de sua preservação. Embora não seja esse o cerne da prática do pesquisador da área, ela é, como o próprio nome sugere, substancial para o desdobramento de outras atividades.

- A função adjetiva está voltada para o viés literário da prática filológica. É, a nosso ver, o centro do trabalho da Crítica Textual, a edição de textos e a preservação de testemunhos. Ponderamos a relevância dessa prática por ser ela a primeira das quais a Filologia deu conta, ainda no seu berço, em Alexandria. A atividade de Crítica Textual, hoje, transformou-se a partir do estabelecimento de métodos de edição (por exemplo, com o método lachmanniano, conforme já expusemos anteriormente), mas ainda carrega, se assim podemos dizer, a 'identidade do fazer filológico'. 
- A função transcendente extrapola os limites dos fólios e compreende, na verdade, a abordagem mais aproximada da que adotamos neste trabalho. É a abordagem do texto enquanto um complexo de elementos de ordem linguística, cognitiva e social. Acreditamos que a concepção de Filologia moderna está, de certo modo, ancorada na função transcendente, pois é no lançar o olhar para além dos fólios, para o texto em sua efetiva atualização, que acreditamos estar o cerne das pesquisas contemporâneas nessa área.

Em trabalho anterior, discutimos, a partir de novas tendências percebidas dentro de pesquisas na área da Filologia e da Linguística, que se faz cada vez mais necessário trabalharmos com a interseção entre essas duas ciências, sobretudo na atualidade, quando se fala tanto de interdisciplinaridade. Desse modo, reiteramos que "resta-nos, sim, aceitarmos que Linguística e Filologia podem caminhar pari passu, pois, por consequência, esta é, desde sua origem, uma ciência da linguagem". (Alves; Ximenes; Santos, 2016, p. 130).

Neste ponto, faz-se necessário levantarmos algumas reflexões a respeito de como a concepção de texto influencia as definições de Filologia aqui apresentadas, e como hoje o status do texto reclama para a Filologia abordagens mais condizentes com a dinamicidade desse objeto. Em Alves, Ximenes e Santos (2016, p. 128), já levantamos essa discussão quando ressaltamos que

\footnotetext{
As análises linguísticas que vêm sendo desenvolvidas dentro do campo dos estudos filológicos reclamam para o texto uma definição bem mais complexa e abrangente que meramente referida à materialidade objetiva, ou seja, aos escritos nos fólios. Logo, se pensamos o texto para além dessa realidade estanque, e incorporamos a esse objeto de estudo da Filologia o status de um "evento comunicativo para o qual convergem ações linguísticas, cognitivas e sociais" (Beaugrande, 1997). Daremos um salto na nossa forma de vermos o trabalho filológico bem como ampliaremos enormemente seu campo de atuação.
}

A respeito dessa questão, os estudos de Lamas (2009), a nosso ver, são os primeiros que buscam propor para a Filologia uma noção de texto pautada em três sentidos: Como sinônimo do dito (oralmente ou escrito); como atividade e como produto; e como totalidade do que é falado, mas para além da finalidade literária, embora compreenda o autor que ela está incluída aí. Na visão de Lamas (2009), esse conceito de texto pode redefinir a "Nova Filologia", que se adaptará aos "novos tempos" e aos "novos objetivos". A partir de suas proposições, esse autor visa uma "Filologia integral", que possa dar conta dos problemas da linguagem.

Ximenes (2013) considera que a proposta de Lamas dissolve as barreiras entre Filologia e Linguística, uma vez que visa incorporar todas as correntes da linguística moderna. Consoante ao que apresenta Lamas (2009), Ximenes (2013, p. 196) afirma que

\footnotetext{
para a análise e interpretação dos textos é necessário penetrar profundamente em todas as vertentes da Linguística, por meio dos elementos do discurso, da pragmática e da língua, enquanto sistemas propriamente ditos vistos tanto sincrônica como diacronicamente.
}

Tendo em vista essas questões, Gama e Telles (2006) entendem a Filologia Textual como uma retomada de posição para o que sempre foi o seu primeiro e último fim: o estudo da cultura de um povo. 
Aproximando-se do que propõe Lamas (2009), atualmente, pelo menos no Brasil, as pesquisas filológicas têm encontrado no viés interdisciplinar uma âncora para a retomada dos estudos na área da edição de manuscritos.

Como prova do que afirmamos, lembramos aqui das palavras de Teixeira, Queiroz e Santos (2006) na apresentação da obra Diferentes perspectivas dos estudos filológicos:

O presente volume é prova testemunhal e cabal de que [a Filologia] se encontra revigorada. Não poderia ser diferente. O tempo e o homem modificam-se, evoluem, adaptam-se às novas descobertas. Em um contexto pluri, multi, trans, interdisciplinar, os estudos filológicos também lançam outros olhares sobre o texto, ampliando o seu espectro de atuação, dialogando, pacífica e harmoniosamente com a literatura, a história, a linguística, a análise do discurso, as ciências do léxico e tantas outras ciências humanas (Teixeira, Queiroz e Santos, 2006, p.13).

A esse leque de ciências com as quais a Filologia "dialoga pacificamente" acrescentamos à fala das autoras a Linguística Textual.

Ora, como afirma Spina (1977), a Filologia não existe se não existe o texto, então, partamos dele para reconfigurarmos, em nossos tempos, o que propomos para uma atual concepção de Filologia, o que nos leva, mais uma vez, a pensarmos na função transcendente apresentada por Spina (1977). Talvez seja essa, por assim dizer, uma 'macrofunção' dessa ciência, uma vez que seu objeto de estudo, ao alcançar cada vez mais uma perspectiva dinâmica, nos convida a extrapolarmos os limites do dito e passarmos para planos mais profundos como o do inferível, por exemplo.

A seguir, aprofundando a discussão a respeito da relação texto e Filologia, ancoramos nossa discussão nos pilares da Linguística Textual, cientes de que as discussões desenvolvidas na área tendem a contribuir para a reconfiguração das pesquisas filológicas.

\section{A LINGUÍSTICA DE TEXTO E SUAS CONTRIBUiÇÕES PARA SE PENSAR A FILOLOGIA}

$\mathrm{Na}$ seção anterior, tentamos apresentar as discussões sobre as diversas formas de se pensar a Filologia desde que se tem conhecimento dessa ciência no mundo ocidental até o que vêm propondo os novos estudiosos na área.

Atualmente, a Filologia carece, nas palavras de Lamas (2009, tradução nossa), de bases sólidas que a destaquem "em qualquer das múltiplas esferas em que o linguístico se apresenta como uma dimensão importante"". Para o referido autor, estudos que consideram a Filologia atrelada aos estudos do texto/discurso são o cimento para se construir a futura especialização dessa ciência. Problematiza Lamas (2009, tradução nossa) que:

\footnotetext{
${ }^{7}$ No original: "Dicho de otro modo, si se integra esta Filología basada em los estudios acerca del texto (para el caso, 'discurso') como unidad superior y básica de los estudios (= de grado, de base) podemos poner sólidos cimientos para una futura especialidad ( = de posgrado) en cualquiera de las múltiples esferas en las que lo lingüístico se presenta como una dimensión importante”.
} 
Trata-se, na realidade, de propor um modelo articulado em que se integrem o cultural, o linguístico, e o literário, mas em que também tenham lugar as demais dimensões da linguagem: a cognitiva, a gramatical e a semântica, a sociocomunicativa e a textual, a variação, a aplicação do linguístico a qualquer uma das esferas da realidade prática, etc. ${ }^{8}$.

É tendo como alicerce essas considerações de Lamas que buscamos estabelecer um laço teórico entre a Filologia e a Linguística Textual, fundamentando nossa discussão sobre dois pilares: o conceito de texto e o conceito de contexto, questões intimamente ligadas. Tentaremos, portanto, apresentar como esses conceitos relacionam-se de modo direto e como a reflexão que suscitamos tende a contribuir para se construir essa especialização das pesquisas filológicas proposta por Lamas (2009).

Desde a segunda metade do século $\mathrm{XX}$, não só a ciência linguística se desenvolveu, mas também suas ramificações adquiriram outras formas fazendo com que, nesse período, surgissem, por exemplo, os estudos do texto e do discurso. Segundo Bentes (2012), o termo 'Linguística de Texto' foi empregado, pela primeira vez, por Harald Weinrich, autor alemão que afirmava ser toda a Linguística necessariamente uma Linguística de Texto. Ressalta a autora que a emergência desses estudos é o resultado de um esforço teórico que buscava

\begin{abstract}
Constituir um outro campo (em oposição ao campo construído pela Linguística Estrutural), que procura ir além dos limites da frase, que procura reintroduzir, em seu escopo teórico, o sujeito e a situação da comunicação, excluídos das pesquisas sobre a linguagem pelos postulados dessa mesma Linguística Estrutural - que compreendia a língua como sistema e como código, com função puramente informativa (Bentes, 2012, p. 259).
\end{abstract}

A fim de discutirmos a perspectiva do texto dentro do escopo teórico da Linguística Textual, precisamos recordar as diversas concepções que esse objeto foi incorporando ao longo do desenvolvimento dos estudos linguísticos condicionados pelas diferentes concepções de linguagem. Diversos pesquisadores que discutem o tema consideram que existem (ou existiram) três correntes de pensamento que se desenvolveram ao longo dos estudos linguísticos: a primeira considerava (considera) a linguagem enquanto expressão do pensamento; a segunda entendia (entende) a linguagem como instrumento de comunicação; e a terceira compreende a linguagem como forma ou um processo de interação. Sinalizamos que, mais recentemente, fala-se em uma quarta abordagem, a respeito da qual discutiremos mais à frente. Por agora, cabe-nos esclarecer de forma bastante resumida cada uma dessas três abordagens iniciais.

Para os que compreendem a linguagem como expressão do pensamento, o fenômeno linguístico é um ato racional, "um ato monológico, individual, que não é afetado pelo outro nem pelas circunstâncias que constituem a situação social em que a enunciação acontece". (Travaglia, 1997, p. 21). Dessa forma, compreendia-se a linguagem como instrumento de manifestação do que se desenvolve internamente no

\footnotetext{
${ }^{8}$ No original: "Se trata, em el fondo, de proponer un modelo articulado em el que se integren lo cultural, lo lingüístico y lo literario, pero em el que también quepan las demás dimensiones del lenguaje: la cognitiva, la gramatical y la semántica, la sociocomunicativa y la textual, la variación, la aplicación de lo lingüístico a cualquiera de las esferas de la realidade práctica, etc.”.
} 
indivíduo. Nesse momento, segundo Marcuschi (2008), a língua foi tomada como um código ou como um sistema de signos. Essa concepção compreende os estudos de Saussure e Chomsky, por exemplo, que não buscam explicações para o fenômeno linguístico além dos elementos internos estruturais da própria língua.

Bakhtin/Volóchinov ${ }^{9}$ (2012, p. 74) denomina essa forma de conceber a língua(gem) como fruto da criação individual de Subjetivismo Idealista. De acordo com esse autor, essa tendência "interessa-se pelo ato da fala, de criação individual como fundamento da língua", e pode ser assim sintetizada:

1. A língua é uma atividade, um processo ininterrupto de construção ("energia") que se materializa sob a forma de atos individuais de fala;

2. As leis da criação linguística são essencialmente as leis da psicologia individual;

3. A criação linguística é uma criação significativa, análoga à criação artística;

4. A língua, enquanto produto acabado (“ergon”), enquanto sistema estável (léxico, gramática, fonética) apresenta-se como um depósito inerte tal como a lava fria da criação linguística, abstratamente construída pelos linguistas com vistas a sua aquisição prática, como instrumento pronto para ser usado. (Bakhtin/Volóchinov, 2012, p. 75-76).

Essa primeira corrente do pensamento linguístico, segundo Koch (2002, p. 16), entende o texto como "um produto - lógico - do pensamento [...] do autor, nada mais cabendo ao leitor/ouvinte senão 'captar' essa representação mental, juntamente com as intenções (psicológicas) do produtor, exercendo, pois, um papel essencialmente passivo". A respeito desse tipo de leitor, evocamos a metáfora machadiana dos vermes presente no romance Dom Casmurro. Passemos a ela:

[...] Cheguei a pegar em livros velhos, livros mortos, livros enterrados, a abri-los, a compará-los, catando o texto e o sentido [...]. Catei os próprios vermes dos livros, para que me dissessem o que havia nos textos roídos por eles. - Meu senhor, respondeu-me um longo verme gordo, nós não sabemos absolutamente nada dos textos que roemos, nem escolhemos o que roemos, nem amamos ou detestamos o que roemos; nós roemos. Não lhe arranquei mais nada. Os outros todos, como se houvessem passado palavra, repetiam a mesma cantilena. Talvez esse discreto silêncio sobre os textos roídos fosse ainda um modo de roer o roído. (Assis, 2016, p. 116, grifo nosso).

Compreendemos que, assim como o personagem Bentinho no trecho apresentado, o filólogo constantemente está em contato com os registros antigos, buscando respostas, questionando, apurando o conhecimento a respeito das informações guardadas pelo tempo. A metáfora dos vermes é, a nosso ver, símbolo de um leitor passivo, aquele que absorve as informações pura e simplesmente, sem agir sobre o que lê ou ouve. Ele está ligado a uma visão clássica de sujeito, alheio às influências externas do mundo que o rodeia. Esse sujeito não sabe absolutamente nada

\footnotetext{
${ }^{9}$ Neste artigo, nos referimos ao autor de Marxismo e filosofia da linguagem no singular, porque entendemos a querela a respeito da real autoria do referido livro. Atualmente, sabemos que a publicação é de autoria de Volóschinov (conforme podemos ver na edição do livro de 2017, pela editora 34, que preserva apenas o nome deste autor). No entanto, como utilizamos ainda uma versão anterior a essa, optamos por citar o nome dos dois autores, mas considerá-los no singular, uma vez que sempre se soube que a publicação era de autoria de apenas um deles.
} 
a respeito dos 'textos' que 'rói' (para insistir na metáfora) e somente detém-se a "roer o roído".

Essa imagem nem de longe pode ser entendida como todo o trabalho filológico, uma vez que a prática de leitura de textos antigos requer zelo, atenção e uma complexa relação de informações que emergem da materialidade dos fólios e precisa ser estudada, remontada, na atividade filológica. Vemos, pois, que a atividade de lidar com textos implica mais que a superficialidade de colher informações nos fólios. Cada palavra surge como um link que nos leva a diversas redes conceituais durante o processo de reconstituição dos fatos, sejam de ordem histórica ou linguística. Tal afirmação nos leva a refutar a primeira visão de texto e, por sua vez, a noção de que a atividade filológica detém-se apenas à extração de informações condensadas na materialidade textual.

A segunda tendência do pensamento linguístico entende a linguagem como instrumento. De acordo com Marcuschi (2008) a principal característica dessa perspectiva é o desvinculamento da língua do seu contexto social, passando a ser vista como um código, um conjunto de signos, combinados através de regras, que possibilitam ao emissor transmitir uma certa mensagem ao receptor. "Além disso, tem como consequência a ideia de que a língua é um instrumento transparente e de manuseio não problemático" (Marcuschi, 2008, p. 60).

Para Travaglia (1997, p. 22), "essa é uma visão monológica e imanente da língua, que a estuda segundo uma perspectiva formalista - que limita esse estudo ao funcionamento interno da língua - e que separa o homem no seu contexto social".

Bakhtin/Volochínov (2012, p. 84), por sua vez, denomina essa concepção de objetivismo abstrato. Segundo ele, essa abordagem tomava o sistema linguístico enquanto estrutura externa e compreendia a língua como um "sistema estável e imutável de formas linguísticas". O autor assim resume essa segunda orientação:

1. A língua é um sistema estável e imutável de formas linguísticas submetidas a uma norma que é transmitida, tal qual, à consciência individual e é peremptória para esta.

2. As leis da língua são essencialmente leis linguísticas específicas que estabelecem ligações entre os signos linguísticos no interior de um sistema fechado. Essas leis são objetivas relativamente a toda consciência subjetiva.

3. As ligações linguísticas nada têm a ver com valores ideológicos (artísticos, cognitivos ou outros). [...] Entre a palavra e seu sentido não existe vínculo natural e compreensível para a consciência nem vínculo artístico.

4. Os atos individuais de fala constituem, do ponto de vista da língua, simples refrações ou variações fortuitas ou mesmo deformações das formas normativas (Bakhtin/Volóchinov, 2012, p. 85).

Segundo expressa Bakhtin/Volochínov (2012, p. 101), essas duas correntes linguísticas preocuparam-se em elaborar "métodos e categorias trabalhando com monólogos mortos" sendo o texto visto "como simples produto da codificação de um emissor a ser decodificado pelo leitor/ouvinte, bastando a este, para tanto, o conhecimento do código, já que o texto, uma vez codificado, é totalmente explícito" (Koch, 2002, p. 16).

A essa concepção podemos associar o trabalho filológico restrito ao estudo da estrutura das línguas, que dedica-se a refletir sobre as normas gramaticas e disseca as 
informações presentes nos textos apenas com o fito de tentar sistematizar ou reconstituir normas da estrutura de uma língua.

A terceira concepção, que compreende a linguagem como forma ou um processo de interação, ao contrário das concepções anteriores, situa a linguagem como o lugar de interação humana e de constituição de relações sociais.

Bakhtin/Volóchinov (2012, p. 131), ao criticar as duas concepções anteriores, por ele denominadas, como já dissemos, de Subjetivismo idealista e Objetivismo abstrato, acrescenta que "toda enunciação monológica, inclusive uma inscrição num monumento, constitui um elemento inalienável da comunicação verbal. Toda enunciação, mesmo na forma imobilizada da escrita, é uma resposta a alguma coisa e é construída como tal". O princípio básico que rege essa terceira concepção do pensamento linguístico é, portanto, o princípio do dialogismo, proposto por Bakhtin e que pode ser assim resumido:

1. A língua como sistema estável de formas normativamente idênticas é apenas uma abstração científica que só pode servir a certos fins teóricos e práticos particulares [...]

2. A língua constitui um processo de evolução ininterrupto que se realiza através da interação verbal social dos locutores.

3. As leis da evolução linguística não são [...] leis da psicologia linguística, mas também não podem ser divorciadas da atividade dos falantes. [...] são essencialmente leis sociológicas.

4. A criatividade da língua não coincide com a criatividade artística nem com qualquer outra forma de atividade ideológica específica. Mas, ao mesmo tempo, [...] não pode ser compreendida independentemente dos conteúdos e valores ideológicos que a ela se ligam.

5. A estrutura da enunciação é puramente social. A enunciação como tal só se torna efetiva entre falantes [...]. (Bakhtin/Volóchinov, 2012, p. 131132, grifos do autor).

Atualmente, compreende-se a abordagem dos fenômenos linguísticos à luz de uma quarta abordagem que seria, talvez, um desdobramento da virada pragmática. Uma das grandes representantes dessa abordagem é Salomão (1999). A autora compreende a linguagem dentro dessa perspectiva como "operadora da conceptualização socialmente localizada através de um sujeito cognitivo, em situação comunicativa real, que produz significados como construções mentais, a serem sancionadas no fluxo interativo" (Salomão, 1999, p. 64).

Para Koch (2008, p. 31), na perspectiva sociocognitivista, "o tipo de relação que se estabelece entre linguagem e cognição é estreito, interno, de mútua construtividade". Seria, portanto, a linguagem o mediador entre o mundo biológico e o mundo social. É importante considerar que tal definição evoca uma noção de contexto enquanto um lugar onde se constroem e reconstroem as significações. $\mathrm{O}$ contexto, na visão de Koch (2008, p. 31), é "o árbitro das tensões entre sistematicidades e indeterminações do dizer e do mostrar, do dito e do implicado". O texto, na visão sociocognitivista, seria o próprio lugar dessa interação onde os "sujeitos ativos se constroem e por ele são construídos". A produção da linguagem, portanto,

constitui atividade interativa altamente complexa de produção de sentidos, que se realiza, evidentemente, com base nos elementos linguísticos presentes na superfície textual e na sua forma de organização, mas requer não apenas a mobilização de um vasto conjunto de saberes, mas, 
sobretudo, a sua reconstrução no momento da interação verbal. (Koch, 2008, p. 31, grifo da autora).

Os filólogos em tempos modernos devem estar atentos ao conceito de texto vigente entre os estudos da Linguística Textual. A definição de Beaugrande (1997), que considera o texto como um "evento comunicativo para o qual convergem ações linguísticas, cognitivas e sociais" reflete, justamente, a forma de se compreender o fenômeno textual nessa quarta abordagem.

Ao falarmos de uma leitura contextualizada dos textos (antigos e modernos), precisamos retomar a proposta de Hanks (2008). Afinal de contas, como considera o próprio autor, hoje em dia, é ponto de consenso em diversas áreas de estudo da linguagem que muito, talvez até tudo que se refere à produção de sentido, depende fundamentalmente do contexto. $\mathrm{O}$ autor afirma que "as práticas discursivas são configuradas por e ajudam a configurar os contextos em vários níveis" (Hanks, 2008, p. 174). Assim, a produção de sentido está intimamente ligada ao contexto, que é tomado dentro da antropologia linguística como integrado por esses níveis sociais, linguísticos antropológicos, cognitivos etc. Assim, define o autor:

\footnotetext{
Contexto é um conceito teórico, estritamente baseado nas relações. Não há contexto que não seja "contexto de", ou "contexto para". Como este conceito é tratado depende de como são construídos os outros elementos fundamentais, incluindo língua(gem), discurso, produção e recepção de enunciados, práticas sociais, dentre outros (Hanks, 2008, p. 174).
}

Contrapondo-se a abordagens que tomaram o contexto "uma estrutura radial cujo ponto central é o enunciado falado" (Hanks, 2008, p. 171), como a teoria dos atos de fala (Austin, 1962) e a interação conversacional (Grice, 1989), Hanks (2008) apresenta duas dimensões do contexto: a emergência e a incorporação/encaixamento.

A primeira definição está mais ligada aos elementos imediatos da interação verbal. "Ela diz respeito à atividade mediada verbalmente, à interação, à co-presença, à temporalidade, em um contexto restrito como um fato sensível, social e histórico" (Hanks, 2008, p. 175). A emergência põe em xeque fatores como a situação momentânea, a relevância do cenário e o campo semiótico; já a incorporação, diz respeito aos aspectos ligados ao enquadramento discursivo, como a inscrição do discurso em quadros socioculturais mais amplos.

Nas palavras do autor:

\begin{abstract}
Incorporação é um processo no tempo, e um estudo adequado do contexto no nível dos campos sociais deve observar a ordem temporal das ocupações, incluindo as ocupações das pessoas, dos objetos, dos lugares, e das ações no curso do tempo das organizações. O campo social tem uma história que transcende qualquer ocupação particular. (Hanks, 2008, p. 190).
\end{abstract}

Assim, de forma resumida, entendemos que "a emergência está associada ao chamado tempo real da produção do enunciado, e a incorporação, ao contexto em larga escala, por outro lado" (Hanks, 2008, p. 175).

Um ponto importante a ser apresentado na proposta de Hanks (2008) é a tomada dos participantes do discurso como peças fundamentais para o contexto, seja ele local ou não-local. Essa proposta também adquire originalidade porque trata essas 
duas dimensões - emergência e incorporação - como atuando simultaneamente. Dessa forma, a situação enunciativa emerge a cada momento e o cenário não é tido como uma mera descrição da cena enunciativa, mas um sistema relevante, no qual projetamse campos semióticos/simbólicos/demonstrativos que são transformados pelas relações entre os signos. A esse respeito, afirmam Bentes e Rezende (2008, p. 41):

\begin{abstract}
as três formações (ou níveis) contextuais distintas(os) (situação, cenário e campo semiótico/simbólico) encontram-se combinadas(os) entre si de tal forma que, no curso da vida social, não há situação que não esteja ligada a um cenário e não há cenário que possa ser separado das semioses. É essa relação ordenada de envolvimento e de ligação entre os níveis que o autor denomina incorporação (embedding). Para ele, estudar as relações entre a produção de linguagem e o contexto, é estudar essas relações de incorporação social.
\end{abstract}

Hanks (2008, p. 189) ressalta que esses elementos projetam-se em novas incorporações, que são realizadas pelo campo social caracterizado pelo autor como “atual, localizado, por sua articulação via relevância, simbolização e evocação indicial".

A proposta de contexto apresentada por Hanks é cara aos estudos filológicos, pois leva-nos a compreender que um estudo de documentos históricos, assim como o estudo de qualquer outra interação social, é dependente do contexto enunciativo em que é produzido. O que nos direciona a investigar o período histórico social em que os textos (documentos) estão inseridos, a fim de fazermos emergir os sentidos ali condensados.

Nesse aspecto, parece um ponto muito importante para nós discutirmos, embora que de forma sucinta, como os postulados teóricos que apresentamos até aqui se relacionam ao exercício de leitura do texto antigo com o qual, de modo mais efetivo, o filólogo depara-se constantemente.

Como entende Marcuschi (2008), compreender enunciados não é uma atividade tão natural, nem fruto de um "treinamento". O autor nos chama a atenção para o fato de que o exercício de compreender textos é bem mais complexo do que se pensa, pois além de habilidade exige interação e trabalho. Nesse direcionamento, compreender seria uma forma de nos inserirmos no mundo e, ao mesmo tempo, agirmos sobre ele a partir das relações dialógicas que permeiam nossas práticas sociais.

Marcuschi (2008) considera que todas as nossas práticas diárias mais efetivas são revestidas de linguagem e que não damos conta de sua complexidade por ela ter um funcionamento tão espontâneo. No entanto, interagir por meio de textos não é uma tarefa fácil, pois como "seres produtores de sentido não somos tão lineares e transparentes quanto seria de desejar, e a compreensão humana depende da cooperação mútua" (Marcuschi, 2008, p. 233). Tais observações nos levam a refletir sobre a efetiva complexidade que norteia nossas ações por meio da linguagem. É interessante observarmos, porém, que a característica que nos ajuda a não ficarmos perdidos em meio a esse processo é justamente a mesma que o complexifica: "o fato de serem as atividades sociais e cognitivas marcadas pela linguagem sempre colaborativas e não atos individuais" (Marcuschi, 2008, p. 23).

O filólogo, antes de tudo (e arriscamos dizer que principalmente), é um leitor de textos. Um leitor atento, crítico e que precisa mobilizar recursos de diversas ordens, histórica, social e linguística, por exemplo, no ato de leitura dos documentos antigos. 
A perspectiva de abordagem da Filologia Textual, a nosso ver, está diretamente relacionada com essa forma de pensar o processo de leitura e interação, por ser entendida por Gama e Telles (2006) como ramificação que dá conta da língua como um sistema complexo de estruturas profundas.

Entendemos que, quando se trata da leitura do texto antigo, o filólogo precisa articular todos os elementos constituintes do sistema complexo de leitura com ainda o agravante do distanciamento contextual em que ele, leitor, encontra-se com relação ao contexto de produção do texto. Por essa razão, entendemos, também, que a abordagem do contexto proposta por Hanks (2008) dialoga muito bem com o exercício de investigação do pesquisador que se coloca a interpretar vestígios de um período antigo.

Acreditamos que o percurso teórico que traçamos auxiliará nossa análise e contribuirá com a nossa proposta. Assumir uma ideia de texto sob a ótica sociocognitivista dentro das pesquisas filológicas implica, a nosso ver, pensar em tudo o que aqui foi dito e explicitado, de modo a não mais assumirmos o fenômeno textual enquanto algo estático, pronto, limitado. Carece, dentro da proposta que assumimos, traçarmos novos rumos e, assim, dinamizarmos as pesquisas que porventura virem neste trabalho um ponto de partida coerente para se pensar a leitura do texto filológico.

\section{ConClusões}

Neste trabalho, que, como dissermos, é um recorte de uma pesquisa mais ampla que desenvolvemos em nossa dissertação de mestrado (Alves, 2016), buscamos fazer um apanhado da história dos estudos filológicos e propomos como podemos pensar o texto, nosso objeto de estudo, dentro dessa área entendendo-o, à luz da Linguística Textual, como "um evento comunicativo em que convergem ações linguísticas, sociais e cognitivas" (Beaugrande, 1997, p. 10).

Este estudo também leva-nos a entender que, na sua atividade de realizar uma "leitura ativa", como denomina Auerbach (1972), além da investigação linguística, o filólogo exerce um profundo trabalho de investigação contextual, histórica e política. Isso porque a língua é o reflexo das experiências de um povo, de suas relações sociais e de suas crenças, costumes etc. Desse modo, ao mergulhar nesse complexo universo da leitura, devemos considerar todos os elementos que asseguram a complexidade desse processo. Uma vez que, situando o texto e tomando-o com base em abordagens mais condizentes com a dinamicidade desse objeto, o filólogo é capaz de fazer inferências, levantar informações e interpretar marcas deixadas por nossos antepassados, preservando essas fontes de informações materiais e culturais de um determinado povo em dada época e lugar.

Outra conclusão importante a que chegamos diz respeito à relevância de considerarmos o processamento dentro das análises dos estudos da Filologia Textual sob uma ótica mais dinâmica, o que nos leva a entender, parafraseando as ideias de Bakhtin/Volóshinov (2012), que mesmo estando diante do texto antigo, não estamos trabalhando com monólogos mortos, isolados, como elucidamos ao trazer a metáfora machadiana dos vermes, mas com a língua "em sua totalidade concreta e viva", situada em um determinado momento histórico-social que precisa ser recuperado, a fim de que o sentido condensado nesses textos possa emergir, atualizando-se aos novos contextos enunciativos - isso porque cada leitura é, na verdade, uma textualização. 
A perspectiva de abordagem da Filologia Textual, a nosso ver, está diretamente relacionada com essa forma de pensar o processo de leitura e interação, por ser entendida por Gama e Telles (2006) como ramificação que dá conta da língua como um sistema complexo de estruturas profundas. Desse modo, defendemos aqui, talvez pretensiosamente, que a abordagem teórica do fenômeno textual, como é tomado no campo da Linguística de Texto, tem muito a contribuir com as pesquisas que tratam do texto como seu objeto. De modo especial, no que toca à Filologia Textual, entendemos que essa interface representa um sopro de ânimo para as pesquisas na área, apontando para a Filologia uma perspectiva mais condizente com o status sociocognitivo do seu objeto de estudo.

\section{REFERÊNCIAS}

Alves LEP. Filologia textual e linguística textual: estudo de textos setecentistas à luz da teoria da acessibilidade [dissertação]. Fortaleza: Centro de Humanidades, Universidade Estadual do Ceará; 2016.

Alves LEP, Ximenes EE, Santos HLG. Para além das traças: desdobramentos contemporâneos das pesquisas filológicas. Revista Philologus. 2016;22(65):121-132. [citado 25 out. 2016]. Disponível em: http://www.filologia.org.br/revista.

Assis JMM. Dom Casmurro. Estabelecimento de texto de Santiago-Almeida MM, introdução de Fischer LA. 1ª ed. São Paulo: Companhia das Letras; 2016.

Auerbach E. Introdução aos estudos literários. Paes JP, tradutor. 12ª ed. São Paulo: Cultrix; 1972.

Austin J. How to do things with words. $2^{\text {a }}$ ed. Cambridge: Harvard University Press; 1962.

Bakhtin M (Volochínov VN). Marxismo e filosofia da linguagem. São Paulo: Hucitec; 2012.

Bassetto BF. Elementos de filologia românica: história externa das línguas. São Paulo: Editora da Universidade de São Paulo; 2001.

Beaugrande RD. New foundations for a science of text and discourse. Freedom of access to knowledge and society through discourse. Norwood: Ablex; 1997.

Bentes AC. Linguística textual. In: Mussalim F, Bentes AC, organizadoras. Introdução à linguística: domínios e fronteiras. 9a ed. São Paulo: Cortez; 2012. p. 261-301.

Bentes AC, Rezende CR. Conceitos, questões e fronteiras [con]textuais. In: Signorini I, organizadora. [Re]discutir texto, gênero e discurso. São Paulo: Parábola Editorial; 2008.

Câmara Jr JM. História da linguística. Petrópolis: Vozes; 1975.

Cambraia CN. Introdução à crítica textual. São Paulo: Martins Fontes; 2005.

Coulmas F. Escrita e sociedade. Bagno M, tradutor. São Paulo: Parábola Editorial; 2014.

Dubois J, et al. Dicionário de linguística. 17ª ed. São Paulo: Cultrix; 2011.

Gabas Jr N. Linguística histórica. In: Mussalim F, Bentes AC, organizadoras. Introdução à linguística: domínios e fronteiras. 9a ed. São Paulo: Cortez; 2012. p. 85-112.

Gama AR, Telles CM. Perspectivas da filologia textual. Revista do GELNE (UFC). 2006;4(1-2):172175. 
Grice P. Logic and conversation. In: Studies in the way of words. Harvard: University Press; 1989.

Hanks WF. Língua como prática social: das relações entre língua, cultura e sociedade a partir de Bourdieu e Bakhtin. São Paulo: Cortez; 2008.

Koch IGV. Desvendando os segredos do texto. $7^{\text {a }}$ ed. São Paulo: Cortez; 2002.

Koch IGV. As tramas do texto. Rio de Janeiro: Nova Fronteira; 2008.

Lamas OL. Bolonia, la filologia y venus ante el espejo. Revista electrónica de estúdios filológicos. 2009;17:online. [citado 20 jan. 2016]. Disponível em https://www.um.es/tonosdigital/znum17/portada/monotonos/monotonos.htm.

Lamas OL. Produção textual, análise de gêneros e compreensão. São Paulo: Parábola Editorial; 2008.

Marquilhas MRB. Filologia. In: Ceia C, organizador. E-Dicionário de termos literários. 2008. [citado 18 jul. 2015]. Disponível em http://edtl.fcsh.unl.pt/encyclopedia/filologia/.

Megale H, Cambraia CN. Filologia portuguesa no Brasil. DELTA - Revista de Documentos de Estudos em Linguística Teórica e Aplicada. 1999;15(especial):1-99.

Queiroz AA. Referenciação e polidez em cartas de amor: o resgate da história de Jayme e Maria por meio da (re)construção de self e do outro. [dissertação]. Fortaleza: Centro de Humanidades, Universidade Estadual do Ceará; 2015.

Righi G. História de la filologia clásica. Barcelona: Editorial Labor; 1967.

Salomão MMM. A questão da construção do sentido e a revisão da agenda dos estudos da linguagem. Veredas: revista de estudos linguísticos. 1999;3(1):61-79.

Santiago-Almeida MM. Para que filologia/crítica textual?. Revista Acta. 2011;1:1-12.

Santos R, Souza AS. Filologia e edição de texto. In: Borges RS, et al., organizadores. Edição de texto e crítica filológica. Salvador: Quarteto; 2012. p. 15-59.

Spina S. Introdução à edótica: crítica textual. São Paulo: Cultrix/EDUSP; 1977.

Teixeira MCR. A filologia textual: o revelar dos aspectos da história. Apresentação ao XII Congresso nacional de linguística e filologia. Rio de Janeiro: Círculo Fluminense de estudos filológicos e linguísticos; 25 a 29 de agosto, 2008.

Teixeira MCR, Queiroz RCR, Santos RB, organizadores. Diferentes perspectivas dos estudos filológicos. Salvador: Quarteto; 2006.

Travaglia LC. Gramática e interação: uma proposta para o ensino de gramática no $1^{\circ}$ e $2^{\circ}$ graus. São Paulo: Cortez; 1997.

Ximenes EE. Fraseologias jurídicas: estudos filológico e linguístico do período colonial. Curitiba: Appris; 2013. 